\title{
KUNJUNGAN ANTENATAL CARE TIDAK SESUAI STANDAR MEMENGARUHI TERJADINYA KOMPLIKASI PERSALINAN DI WILAYAH KERJA PUSKESMAS KARANG ANYAR KECAMATAN BERINGIN KABUPATEN DELI SERDANG TAHUN 2014
}

\author{
Rismahara Lubis, Yusniar Siregar, Irma Linda \\ Jurusan Kebidanan Poltekkes Kemenkes Medan
}

\begin{abstract}
Abstrak
Berdasarkan data Riskesdas 2013 cakupan pemeriksaan kehamilan pertama pada trimester pertama adalah 81,6\% dan frekuensi ANC 1-1-2 atau K4 sebesar 70,4\% (Balitbangkes, 2013), sementara berdasarkan data dari Profil Kesehatan Kabupaten Deli Serdang tahun 2012 cakupan kunjungan ibu hamil K1 sebesar 98,16\% dan K4 sebesar 95,91\%. Cakupan K1 dan K4 di Puskesmas Karang Anyar Kecamatan Beringin Deli Serdang tahun 2012 sebesar 98,56\% dari target pencapaian nasional 94\% dan K4 95,42\% dari target pencapaian nasional sebesar $84 \%$, namun masih ditemukan kematian ibu akibat komplikasi persalinan dan masa nifas. Pada tahun 2013 puskesmas Karang Anyar memiliki jumlah kematian ibu terbanyak dari seluruh puskesmas di Kabupaten Deli Serdang yaitu 3 kasus kematian ibu yang disebabkan Eklampsi 2 kasus dan Infeksi 1 kasus (sumber Dinas Kesehatan Kabupaten Deli Serdang). Penelitian ini bertujuan untuk mengetahui pengaruh kunjungan Antenatal Care dan deteksi risiko kehamilan terhadap komplikasi penolong persalinan di wilayah kerja puskesmas Karang Anyar Kecamatan Beringin Kabupaten Deli Serdang tahun 2014. Penelitian ini merupakan survei analitik dengan pendekatan explanatory research. Dilaksanakan mulai Bulan Mei sampai dengan bulan Agustus Tahun 2014. Populasi dalam penelitian ini adalah seluruh ibu hamil trimester ketiga yang diikuti sampai ibu tersebut melahirkan yang berdomisili di wilayah kerja puskesmas Karang Anyar Kecamatan Beringin Kabupaten Deli Serdang pada bulan Mei 2014 sebanyak 98 orang. Penentuan sampel secara total populasi. Analisis statistik yang digunakan adalah uji statistik chisquare $\left(\chi^{2}\right)$, dengan tingkat kemaknaan $p<0.05$ dan uji regresi logistik ganda. Hasil penelitian menunjukkan 75,5\% responden melakukan kunjungan ANC sesuai dengan standard, 76,5\% responden terdeteksi risiko kehamilan dan 22,4\% responden mengalami komplikasi persalinan. Dari hasil analisis multivariat dengan uji regresi logistik ganda menunjukkan bahwa variabel kunjungan ANC dengan $p$ value $0,001(p<0,05)$ dan deteksi resiko kehamilan dengan $p$ value $0,001(p<0,05)$ berpengaruh terhadap komplikasi persalinan di wilayah kerja Puskesmas Karang Anyar Kecamatan Beringin Kabupaten Deli Serdang. Variabel yang paling dominan memengaruhi komplikasi persalinan di wilayah kerja Puskesmas Karang Anyar Kecamatan Beringin Kabupaten Deli Serdang adalah variabel kunjungan ANC yaitu pada nilai koefisien regresi exp (B) 78,900. Disarankan kepada Kepada Dinas Kesehatan Kabupaten Deli Serdang untuk merencanakan program pelatihan guna peningkatan kualitas pelayanan antenatal bagi tenaga kesehatan khususnya bidan yang ada di Kabupaten Deli Serdang.
\end{abstract}

Kata kunci : Kunjungan Ante Nata Care, deteksi risiko kehamilan dan komplikasi persalinan

\section{PENDAHULUAN}

\section{Latar Belakang}

Angka kematian dan kesakitan pada ibu dan bayi di Indonesia masih tetap tinggi bahkan tertinggi di antara negara-negara ASEAN. Menurut data hasil Survei Demografi Kesehatan Indonesia (SDKI) 2012, Angka Kematian Ibu (AKI) di Indonesia menunjukkan kenaikan dari 228 di tahun 2007 menjadi 359 kematian ibu per 100.000 kelahiran hidup di tahun 2012, dan Angka Kematian Bayi (AKB) 32 per 1.000 kelahiran hidup (Badan Pusat Statistik, 2013). Berdasarkan kesepakatan global (Millenium Development Goals/MDGs, 2000) pada tahun 2015 diharapkan AKI dan AKB menurun sebesar tiga perempatnya dalam kurun waktu 1990-2015, Angka Kematian Bayi dan Angka Kematian Balita menurun sebesar dua-pertiga dalam kurun waktu 1990-2015. Berdasarkan hal itu Indonesia mempunyai komitmen untuk menurunkan AKI menjadi 102 per 100.000 kelahiran hidup, dan AKB menjadi 23 per 1.000 kelahiran hidup pada tahun 2015 (Depkes, 2009).

Tingginya AKI secara nasional juga tercermin di tingkat propinsi, termasuk di Propinsi Sumatera 
Utara. Berdasarkan Profil Kesehatan Sumatera Utara tahun 2012, AKI di Sumatera Utara mengalami penurunan dari 328 per 100.000 kelahiran hidup di tahun 2010, menjadi 106 per 100.000 kelahiran hidup di tahun 2012, namun ini belum bisa menggambarkan AKI yang sebenarnya di populasi. (Dinkes Provinsi Sumatera Utara, 2013).

Jumlah kematian ibu di Kabupaten Deli Sedang berdasarkan Profil Kesehatan Kabupaten Deli Serdang tahun 2012 terdapat 15 kasus dalam 38.573 kelahiran hidup dengan rincian 1 orang ibu hamil, 9 orang ibu bersalin dan 5 orang ibu masa nifas. Kabupaten Deli Serdang merupakan salah satu kabupaten dari 5 kabupaten di Sumatera Utara yang dilibatkan dalam program Expanding Maternal and Neonatal Survival (EMAS). Program EMAS merupakan program hasil kerja sama antara Pemerintah Indonesia dengan lembaga donor Badan Pembangunan Internasional Amerika Serikat (USAID), yang bertujuan untuk menurunkan AKI dan AKB di Indonesia sebesar 25\%. (Propil Kesehatan Kabupaten Deli Serdang Tahun 2013).

Kematian ibu dibedakan menjadi dua kelompok yaitu: (1) Direct obstetric deaths, yaitu kematian ibu yang langsung disebabkan oleh komplikasi obstetri pada masa hamil, bersalin dan nifas, atau kematian yang disebabkan oleh suatu tindakan, atau berbagai hal yang terjadi akibat tindakan-tindakan tersebut yang dilakukan selama hamil, bersalin atau nifas, dan (2) Indirect obstetric deaths, yaitu kematian ibu yang disebabkan oleh suatu penyakit yang bukan komplikasi obstetri, yang berkembang atau bertambah berat akibat kehamilan atau persalinan. Di negara berkembang sekitar $95 \%$ kematian ibu termasuk dalam kelompok direct obstetric deaths (Depkes, 2007).

Penyebab langsung kematian ibu biasanya terkait erat dengan kondisi kesehatan ibu sejak proses kehamilan, persalinan dan nifas. Penyebab langsung kematian ibu maternal adalah perdarahan (28\%), eklampsia (24\%), infeksi (11\%), komplikasi puerpurium (8\%), abortus (5\%), partus macet/lama (5\%), trauma obstetrik (5\%), emboli obstetrik (5\%), dan penyebab lainnya (11\%). Sedangkan penyebab tidak langsung kematian ibu maternal adalah bumil anemia (51\%), terlalu muda usia <20 tahun (10\%), terlalu tua usia $>35$ tahun $(11 \%)$, terlalu banyak anak $>3-4$ orang $(19 \%)$, terlalu dekat jarak kelahiran <24 bulan (15\%), dan jarak <36 bulan (36\%) (Depkes, 2008). Sementara penyebab tidak langsung lebih terkait dengan kondisi sosial, ekonomi, geografis serta perilaku budaya masyarakat yang terangkum dalam Empat Terlalu (terlalu muda usia, terlalu tua usia, terlalu banyak anak, terlalu rapat kehamilan) dan Tiga Terlambat (terlambat mengambil keputusan, terlambat membawa ke fasilitas kesehatan, terlambat mendapat pelayanan pelayanan kesehatan). Risiko kematian ibu maternal dapat terjadi sejak awal kehamilan hingga pasca persalinan/nifas dengan risiko paling tinggi terjadi pada periode persalinan (Depkes, 2001).
Perkembangan data terbaru dari Riset Kesehatan Dasar (Riskesdas) 2013, hampir seluruh ibu hamil di Indonesia $(95,4 \%)$ sudah melakukan pemeriksaan kehamilan (K1) dan frekuensi kehamilan minimal 4 kali selama masa kehamilannya adalah $83,5 \%$. Adapun untuk cakupan pemeriksaan kehamilan pertama pada trimester pertama adalah $81,6 \%$ dan frekuensi ANC 1-1-2 atau K4 (minimal 1 kali pada trimester pertama, minimal 1 kali pada trimester kedua dan minimal 2 kali pada trimester3) sebesar 70,4\%. Persalinan di fasilitas kesehatan adalah 70,4\% dan masih terdapat $29,6 \%$ di rumah/lainnya. Penolong persalinan oleh tenaga kesehatan yang kompeten (dokter spesialis, dokter umum dan bidan) mencapai $87,1 \%$, namun masih bervariasi antar provinsi (Balitbangkes, 2013).

Berdasarkan data dari profil kesehatan Kabupaten Deli Serdang tahun 2012 cakupan kunjungan ibu hamil K1 sebesar 98,16\% dan K4 sebesar 95,91\%. Cakupan K1 dan K4 di Puskesmas Karang Anyar Kecamatan Beringin Deli Serdang tahun 2012 sebesar 98,56\% dari target pencapaian nasional 94\% dan K4 95,42\% dari target pencapaian nasional sebesar $84 \%$. Namun masih ditemukan kematian ibu akibat komplikasi persalinan dan masa nifas, pada tahun 2013 puskesmas Karang Anyar memiliki AKI terbanyak dari seluruh puskesmas di Kabupaten Deli Serdang yaitu 3 kasus kematian ibu yang disebabkan Eklampsi 2 kasus dan Infeksi 1 kasus (sumber Dinas Kesehatan Kabupaten Deli Serdang).

Kasus kehamilan risiko banyak ditemukan di masyarakat, tetapi tenaga kesehatan tidak bisa menemukannya satu persatu, karena itu peran serta bidan sangat dibutuhkan dalam mendeteksi ibu hamil risiko. Salah satu tindakan bidan yaitu melalui promosi kesehatan dan pencegahan risiko, seperti pemberian suplemen nutrisi, zat besi, imunisasi tetanus toksoid dan pemberian konseling tentang tanda bahaya kehamilan, dan keluarga berencana. Mendeteksi dan melakukan penatalaksanaan penyakit hipertensi dan diabetes mellitus (Muslihatun, 2009).

Berdasarkan data yang diperoleh dari profil kesehatan Dinas Kesehatan Kabupaten Deli Serdang tahun 2012, jumlah ibu hamil sebanyak 42.431 jiwa, ibu hamil yang mengalami risiko sebanyak 8.486 jiwa $(19,99 \%)$ yang bersumber dari 34 puskesmas. Dari 34 Puskesmas tersebut, Puskesmas Karang Anyar memiliki jumlah ibu hamil risiko tinggi/komplikasi sebanyak 153 jiwa dari 765 ibu hamil (20\%) (Propil Dinas Kesehatan Deli Serdang, 2013).

\section{Tujuan Penelitian}

Untuk mengetahui pengaruh kunjungan Ante Natal Care (ANC) dan deteksi risiko kehamilan terhadap komplikasi persalinan di wilayah kerja Puskesmas Karang Anyar Kecamatan Beringin Kabupaten Deli Serdang tahun 2014.

Secara khusus 
1. Untuk mengetahui gambaran komplikasi persalinan di wilayah kerja Puskesmas Karang Anyar Kecamatan Beringin Kabupaten Deli Serdang tahun 2014.

2. Untuk mengetahui pengaruh kunjungan Ante Natal Care (ANC) terhadap komplikasi persalinan di wilayah kerja Puskesmas Karang Anyar Kecamatan Beringin Kabupaten Deli Serdang tahun 2014.

3. Untuk mengetahui pengaruh deteksi risiko kehamilan terhadap komplikasi persalinan di wilayah kerja Puskesmas Karang Anyar Kecamatan Beringin Kabupaten Deli Serdang tahun 2014

\section{Manfaat Penelitian}

Manfaat penelitian diharapkan dapat memberikan informasi khususnya kepada pengambil kebijakan dalam pelayanan kesehatan sebagai data dan bahan masukan dalam merumuskan perencanaan kebijakan dan program kerja dalam upaya mengurangi kejadian komplikasi persalinan untuk menekan jumlah kematian ibu.

\section{METODE PENELITIAN}

\section{Desain Penelitian}

Jenis penelitian yang dilakukan adalah survei analitik dengan pendekatan explanatory research yang

\section{Tempat dan Waktu}

Penelitian dilakukan di wilayah kerja puskesmas Karang Anyar Kecamatan Beringin Kabupaten Deli Serdang. Penelitian direncanakan dilakukan mulai bulan Mei sampai dengan Agustus 2014.

\section{Populasi dan sampel}

Populasi dalam penelitian ini adalah seluruh ibu hamil trimester ketiga yang berdomisili di wilayah kerja puskesmas Karang Anyar Kecamatan Beringin Kabupaten Deli Serdang. Jumlah sampel dalam penelitian ini sebanyak 98 orang dan seluruh populasi dijadikan sampel penelitian (total populasi).

\section{HASIL PENELITIAN}

\section{Gambaran Umum Lokasi Penelitian}

Puskesmas Karang Anyar terletak di Kecamatan Beringin Kabupaten Deli Serdang. Kecamatan ini merupakan salah satu kecamatan yang terletak di daerah dataran rendah. Secara geografis Kecamatan Beringin mempunyai luas wilayah 12.492

\section{Analisis Univariat Komplikasi Persalinan}

Tabel 4.1. Distribusi frekuensi komplikasi persalinan di wilayah kerja Puskesmas Karang Anyar Kec. Beringin Kab. Deli Serdang Tahun 2014

\begin{tabular}{cccc}
\hline No & Komplikasi Persalinan & F & \% \\
\hline 1 & Tidak Ada Komplikasi & 76 & 77,6 \\
2 & Ada Komplikasi & 22 & 22,4 \\
\hline & Total & $\mathbf{9 8}$ & $\mathbf{1 0 0}$ \\
\hline
\end{tabular}

Berdasarkan tabel di atas dapat dilhat bahwa komplikasi persalinan di Wilayah Kerja Puskesmas Karang Anyar Kecamatan Beringin Kabupaten Deli Serdang lebih banyak dengan tidak ada komplikasi yaitu 76 orang $(77,6 \%)$.

\section{Kunjungan ANC dan Deteksi Risiko Kehamilan}

\begin{tabular}{|c|c|c|c|}
\hline No & Kunjungan ANC & $\mathbf{f}$ & $\%$ \\
\hline 1 & Sesuai Standar & 74 & 75,5 \\
\hline 2 & Tidak Sesuai Standar & 24 & 24,5 \\
\hline No & Deteksi Resiko Kehamilan & $\mathbf{F}$ & $\%$ \\
\hline 1 & Terdeteksi & 75 & 76,5 \\
\hline \multirow[t]{2}{*}{2} & Tidak Terdeteksi & 23 & 23,5 \\
\hline & Total & 98 & 100 \\
\hline
\end{tabular}

Berdasarkan tabel diatas dapat dilhat bahwa kunjungan ANC lebih banyak kunjungan sesuai standar sebanyak 74 orang $(75,5 \%)$ dan deteksi resiko kehamilan di Wilayah Kerja Puskesmas Karang Anyar Kecamatan Beringin Kabupaten Deli Serdang lebih banyak dengan terdeteksi yaitu 75 orang $(76,5 \%)$.

\section{Karakteristik Responden}

Tabel 4.1. Distribusi Frekuensi Umur, pendidikan dan pekerjaan Responden di Wilayah Kerja Puskesmas Karang Anyar Kec. Beringin Kab. Deli Serdang Tahun 2015

\begin{tabular}{|c|c|c|c|}
\hline No & Variabel & $\mathbf{F}$ & $\%$ \\
\hline & a. Umur Responden & & \\
\hline 1 & $\leq 19$ Tahun & 5 & 5,1 \\
\hline 2 & 20-35 Tahun & 84 & 85,7 \\
\hline \multirow[t]{3}{*}{3} & $>35$ Tahun & 9 & 9,2 \\
\hline & Total & 98 & 100 \\
\hline & b. Pendidikan Responden & & \\
\hline 1 & $\mathrm{SD} / \mathrm{MI}$ & 9 & 9,2 \\
\hline 2 & SMP/Sederajat & 19 & 19,4 \\
\hline 3 & SMA/Sederajat & 67 & 68,4 \\
\hline \multirow[t]{3}{*}{4} & Perguruan Tinggi & 3 & 3,1 \\
\hline & Total & 98 & 100 \\
\hline & c.Pekerjaan Responden & & \\
\hline 1 & PNS & 1 & 1,0 \\
\hline 2 & Pegawai Swasta & 3 & 3,1 \\
\hline 3 & Petani & 18 & 19,4 \\
\hline 4 & Buruh & 3 & 3,1 \\
\hline \multirow[t]{2}{*}{5} & Tidak Bekerja & 73 & 74,5 \\
\hline & Total & 98 & 100 \\
\hline
\end{tabular}


Berdasarkan tabel di atas dapat dilhat bahwa umur responden di Wilayah Kerja Puskesmas Karang Anyar Kecamatan Beringin Kabupaten Deli Serdang lebih banyak dengan umur 20-35 tahun sebanyak 84 orang (85,7\%), pendidikan responden lebih banyak dengan pendidikan SMA/Sederajat sebanyak 67 orang $(68,4 \%)$ dan pekerjaan lebih banyak dengan tidak bekerja yaitu 73 orang $(74,5 \%)$. Dari data Puskesmas diperoleh bahwa cakupan ANC untuk KI dan K4 tahun 2013 sudah mencapai target (98\%).

\section{Analisis Bivariat}

Tabel 4.7. Hubungan Kunjungan ANC dengan Komplikasi Persalinan di Wilayah Kerja Puskesmas Karang Anyar Kecamatan Beringin Kabupaten Deli Serdang Tahun 2014

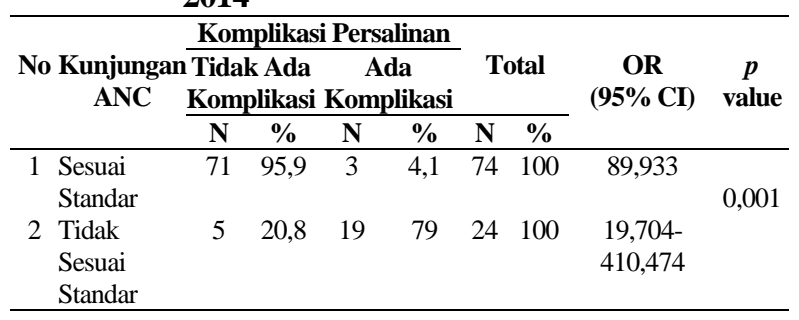

Berdasarkan tabel di atas dapat dilihat bahwa dari 74 responden yang melakukan kunjungan ANC sesuai standar ditemukan hanya 3 orang $(4,1 \%)$ yang mengalami komplikasi dan dari 24 responden yang kunjungan ANC tidak sesuai standar ditemukan 19 orang $(79,2 \%)$ yang mengalami komplikasi.

Hasil uji statistik chi square menunjukkan bahwa diperoleh nilai $p<0,05$ maka dapat disimpulkan ada perbedaan proporsi komplikasi persalinan antara ibu dengan kunjungan ANC sesuai standar dengan ibu yang kunjungan ANC tidak sesuai standar (ada hubungan yang signifikan antara kunjungan ANC dengan komplikasi persalinan). Dari hasil analisis diperoleh pula nilai OR 89,933 $(95 \% \mathrm{CI}=19,704-$ $410,474)$ artinya ibu dengan kunjungan ANC tidak sesuai standar mempunyai kemungkinan 89,9 kali terjadi komplikasi dibandingkan ibu dengan kunjungan ANC sesuai standar.

Tabel 4.8. Hubungan Deteksi Risiko Kehamilan dengan Komplikasi Persalinan di Wilayah Kerja Puskesmas Karang Anyar Kecamatan Beringin Kabupaten Deli Serdang Tahun 2015

\begin{tabular}{|c|c|c|c|c|c|c|c|c|}
\hline \multirow{3}{*}{ No } & \multirow{3}{*}{$\begin{array}{c}\text { Deteksi } \\
\text { Resiko } \\
\text { Kehamilan }\end{array}$} & \multicolumn{4}{|c|}{ Komplikasi Persalinan } & \multirow[b]{2}{*}{ Total } & \multirow{3}{*}{$\begin{array}{c}\text { OR } \\
(95 \% \mathrm{CI})\end{array}$} & \multirow{3}{*}{ P value } \\
\hline & & \multicolumn{2}{|c|}{$\begin{array}{l}\text { Tidak Ada } \\
\text { Komplikasi }\end{array}$} & \multicolumn{2}{|c|}{$\begin{array}{c}\text { Ada } \\
\text { Komplikasi }\end{array}$} & & & \\
\hline & & $\mathbf{N}$ & $\%$ & $\mathbf{N}$ & $\%$ & $\mathbf{N}$ & & \\
\hline & erdeteksi & 71 & 94,7 & 4 & 5,3 & $75 \quad 100$ & 63,900 & \\
\hline & $\begin{array}{l}\text { idak } \\
\text { erdeteksi }\end{array}$ & 5 & 21,7 & 18 & 78,3 & 23100 & $\begin{array}{l}15,556- \\
262,481\end{array}$ & 0,001 \\
\hline
\end{tabular}

Berdasarkan tabel di atas dapat dilihat bahwa ada sebanyak 75 orang responden yang terdeteksi risiko kehamilannya ditemukan $4(5,3 \%)$ yang mengalami komplikasi persalinan, sedangkan dari 23 responden yang tidak terdeteksi risiko kehamilan 18 (78,2\%) yang mengalami komplikasi persalinan.

Hasil uji statistik chi square menunjukkan bahwa diperoleh nilai $p<0,05$ maka dapat disimpulkan ada perbedaan proporsi komplikasi persalinan antara ibu yang terdeteksi resiko kehamilan dengan ibu yang tidak terdeteksi kehamilan (ada hubungan yang signifikan antara deteksi resiko kehamilan dengan komplikasi persalinan). Dari hasil analisis diperoleh pula nilai OR 63,900 (95\% CI $=15,556-262,481)$ artinya ibu yang tidak terdeteksi risiko kehamilannya mempunyai kemungkinan 63,9 kali dapat terjadi komplikasi persalinan dibandingkan ibu yang terdeteksi risiko kehamilan.

\section{Analisis Multivariat}

Tabel 4.9. Pengaruh Kunjungan ANC dan Deteksi Resiko Kehamilan Terhadap Komplikasi Persalinan Wilayah Kerja Puskesmas Karang Anyar Kecamatan Beringin Kabupaten Deli Serdang.

\begin{tabular}{lccccc}
\hline \multicolumn{1}{c}{$\begin{array}{c}\text { Variabel } \\
\text { Independen }\end{array}$} & $\begin{array}{c}\text { Nilai } \\
\text { B }\end{array}$ & $\begin{array}{c}\text { Nilai } \\
\boldsymbol{p}\end{array}$ & $\boldsymbol{E x p}(\mathbf{B})$ & 95\% C.I.for $\operatorname{Exp}(\mathbf{B})$ \\
\hline & & & & Lower & Uppr \\
\hline $\begin{array}{l}\text { Kunjungan } \\
\text { ANC }\end{array}$ & 4.368 & 0,001 & 78.900 & 8.424 & 738.989 \\
$\begin{array}{l}\text { Deteksi Resiko } \\
\text { ANC }\end{array}$ & 4.018 & 0,001 & 55.580 & 5.816 & 531.148 \\
Constant & -4.679 & 0,001 & .009 & & \\
\hline
\end{tabular}

Berdasarkan tabel di atas, dapat terlihat bahwa pengujian terhadap hipotesis yang menyatakan bahwa kunjungan ANC dan deteksi resiko kehamilan berpengaruh terhadap komplikasi persalinan di wilayah kerja Puskesmas Karang Anyar Kecamatan Beringin Kabupaten Deli Serdang dilakukan dengan uji regresi logistik ganda dengan metode enter dengan nilai signifikansi masing-masing variabel $p<0,05$.

Hasil analisis uji regresi logistik ganda juga menunjukkan bahwa variabel kunjungan ANC dengan pvalue $0,001 \quad(p<0,05)$ dan deteksi resiko kehamilan dengan pvalue $0,001 \quad(p<0,05)$ berpengaruh terhadap komplikasi persalinan di wilayah kerja Puskesmas Karang Anyar Kecamatan Beringin Kabupaten Deli Serdang.

Hasil analisis uji regresi logistik ganda menunjukkan bahwa variabel yang paling dominan memengaruhi komplikasi persalinan di wilayah kerja Puskesmas Karang Anyar Kecamatan Beringin Kabupaten Deli Serdang adalah variabel kunjungan ANC yaitu pada nilai koefisien regresi exp (B) 78,900. Hal ini menunjukkan variabel tersebut memiliki pengaruh yang signifikan terhadap komplikasi persalinan di wilayah kerja Puskesmas Karang Anyar Kecamatan Beringin Kabupaten Deli Serdang.

Variabel kunjungan ANC bernilai positif menunjukkan bahwa variabel tersebut mempunyai pengaruh yang searah (positif) terhadap komplikasi persalinan di wilayah kerja Puskesmas Karang Anyar Kecamatan Beringin Kabupaten Deli Serdang. Jadi dapat ditafsirkan secara teoritis bahwa komplikasi persalinan di wilayah kerja Puskesmas Karang Anyar Kecamatan Beringin Kabupaten Deli Serdang akan 
menurun jauh apabila terjadi peningkatan kunjungan ANC.

Pada tabel 4.9 juga terlihat bahwa variabel deteksi resiko kehamilan bernilai positif menunjukkan bahwa variabel tersebut mempunyai pengaruh yang searah (positif) terhadap komplikasi persalinan di wilayah kerja Puskesmas Karang Anyar Kecamatan Beringin Kabupaten Deli Serdang pada nilai koefisien regresi exp (B) 55,580.

Berdasarkan hasil analisis regresi logistik ganda, variabel kunjungan ANC diperoleh nilai Exp (B) atau Odds Ratio (OR) sebesar 78,900pada Confidence Interval $95 \%$ yaitu antara 8,424 sampai 738,989, sehingga dapat disimpulkan bahwa ibu yang melaksanakankunjungan ANC mempunyai kemungkinan 78,9 kali akan tidak terjadi komplikasi persalinan dibandingkan ibu yang tidak melakukan kunjungan ANC. Variabel deteksi resiko kehamilan diperoleh nilai Exp (B) atau Odds Ratio (OR) sebesar 55,580pada Confidence Interval $95 \%$ yaitu antara 5,816 sampai 531,148, sehingga dapat disimpulkan bahwa ibu yang mendapatkan deteksi resiko kehamilan mempunyai kemungkinan 55,5 kali akan tidak terjadi komplikasi persalinan dibandingkan ibu yang tidak deteksi resiko kehamilan.

Berdasarkan hasil analisis regresi logistik ganda tersebut dapat ditentukan model persamaan regresi logistik ganda yang dapat menafsirkan kunjungan ANC dan deteksi resiko kehamilan yang memengaruhi variabel komplikasi persalinan di wilayah kerja Puskesmas Karang Anyar Kecamatan Beringin Kabupaten Deli Serdang adalah sebagai berikut:

$$
\begin{array}{ll}
\mathrm{f}(\mathrm{Z}) & = \\
& 1+\mathrm{e}^{-(--4,679+4,368+4.018)} \\
\mathrm{f}(\mathrm{Z}) & =\text { Probabilitas Komplikasi Persalinan } \\
\alpha & =\text { Konstanta } \\
\beta_{1}-B_{5} \quad=\text { Koefisien regresi } \\
\mathrm{X}_{1} \quad=\text { Kunjungan ANC } \\
\mathrm{X}_{2} \quad=\text { Deteksi Resiko ANC } \\
\mathrm{f}(\mathrm{Z}) \quad=0,9754
\end{array}
$$

Dengan model persamaan regresi di peroleh ramalan tentang probabilitas responden yang tidak mengalami komplikasi persalinan untuk kunjungan antenatal sesuai standar dan deteksi risiko dalam kehamilan sebesar 0,9754, artinya bila kunjungan antenatal sesuai standar dan dilakukan deteksi risiko kehamilan kemungkinan ibu tidak mengalami komplikasi dalam persalinan sebesar 97,5\%.

\section{PEMBAHASAN}

\section{Kunjungan ANC}

Kunjungan antenatal dikatakan sesuai standar apabila ibu melakukan pemeriksaan pertama kali ke petugas kesehatan pada usia kehamilan kurang dari 14 minggu minimal 1 kali, pada usia kehamilan antara 1428 minggu minimal 1 kali pemeriksaan dan pada saat usia kehamilan setelah 28 minggu sampai menjelang persalinan minimal 2 kali melakukan pemeriksaan (Depkes RI, 2009).
Berdasarkan hasil penelitian ditemukan bahwa bahwa kunjungan ANC di Wilayah Kerja Puskesmas Karang Anyar Kecamatan Beringin Kabupaten Deli Serdang lebih banyak kunjungan sesuai standar sebanyak 74 orang $(75,5 \%)$ dan ditemukan 24 orang $(24,5 \%)$ pemeriksaan ANC tidak sesuai standar. Penelitian ini sesuai dengan Deswani (2003) yang meneliti tentang kedatangan pada kunjungan pertama ke pelayanan antenatal menemukan $22,9 \%$ ibu hamil terlambat datang ke pelayanan antenatal. Penelitian Ginting (2001) di Kecamatan Pesangrahan Jakarta Selatan menemukan hampir 40,2\% ibu hamil tidak memanfaatkan pelayanan antenatal sesuai standar dan $11,4 \%$ tidak pernah memanfaatkan pelayanan antenatal. Demikian juga dengan hasil penelitian Adri (2008) ibu hamil yang melakukan pemeriksaan kehamilan dengan kategori sesuai standar sebesar $69,4 \%$ dan 30,6\% melakukan pemeriksaan kehamilan tetapi frekuensinya tidak sesuai dengan umur kehamilannya sehingga dikategorikan tidak sesuai standar.

\section{Deteksi Risiko Kehamilan}

Hasil penelitian tentang deteksi risiko kehamilan di Wilayah Kerja Puskesmas Karang Anyar Kecamatan Beringin Kabupaten Deli Serdang ditemukan 23 orang $(23,5 \%)$ kejadian risiko tinggi tidak terdeteksi pada masa kehamilan. Keadaan ini lebih tinggi dari data Puskesmas Karang Anyar Kecamatan Beringin pada tahun 2013 yang menunjukkan jumlah ibu hamil risiko tinggi sebanyak $20 \%$.

Hasil penelitian ini sejalan dengan data PWS-KIA Puskesmas Bangetayu tahun 2009 ditemukan 154 orang ibu hamil mengalami risiko kehamilan dari 809 orang (19\%) (Dewi, 2010).

Deteksi risiko pada masa kehamilan merupakan kegiatan yang dilakukan untuk menemukan ibu hamil yang mempunyai faktor risiko. Penjaringan kasus risiko pada masa kehamilan memungkinkan untuk dilakukan penanganan yang sesuai sehingga diharapkan dapat menekan terjadinya komplikasi pada masa persalinan.

\section{Komplikasi Persalinan}

Komplikasi persalinan merupakan suatu kegawatdaruratan obstetrik yang paling sering menyebabkan kematian pada ibu melahirkan. Banyak hal yang dapat menyebabkan terjadinya komplikasi persalinan yaitu status kesehatan ibu yang buruk, status kesehatan reproduksinya, akses ke peyananan kesehatan serta perilaku yang kurang baik dari ibu itu sendiri (Misar, dkk, 2012).

Hasil penelitian menunjukkan bahwa komplikasi persalinan di Wilayah Kerja Puskesmas Karang Anyar Kecamatan Beringin Kabupaten Deli Serdang tahun 2014 ditemukan ada 22 kasus $(22,4 \%)$ terdiri dari laserasi jalan lahir $36,4 \%$, pre eklampsi dan infeksi masing-masing 27,3\%, retensio dan malposisi masing-masing $0,45 \%$.

Hasil penelitian ini sesuai dengan Depkes (1997) bahwa 15-20 \% kehamilan normal dapat berubah menjadi komplikasi pada saat persalinan. Hasil penelitian Armagustini (2010) tentang determinan 
kejadian komplikasi persalinan di Indonesia ditemukan $10,6 \%$ ibu bersalin yang mengalami komplikasi.

Salah satu cara yang efektif untuk mencegah terjadinya komplikasi persalinan adalah melalui deteksi dini risiko tinggi kehamilan dengan cara pemeriksaan yang teratur ke petugas kesehatan dan mendapat pelayanan yang adekuat.

Pengaruh Kunjungan ANC terhadap Komplikasi Persalinan di Wilayah Kerja Puskesmas Karang Anyar Kecamatan BeringinKabupaten Deli Serdang.

Hasil penelitian tentang variabel kunjungan ANC ditemukan ibu yang sesuai standar kunjungan ANC dengan proporsi tidak ada komplikasi persalinan95,9\%. Uji statistik regresi logistic ganda menunjukkan variabel kunjungan ANC nilai $\mathrm{p}<0,05$ dengan ods rasio78,900(95\% CI $=8,424-738,989)$ berpengaruh terhadap komplikasi persalinan. Mengacu pada hasil uji tersebut dapat dijelaskan semakin tinggi kunjungan ANC akan meningkat tidak ada komplikasi persalinan. Pada penelitian ini perlu peningkatan kunjungan ANC pada ibu saat hamil karena ibu yang tidak sesuai standar kunjungan ANC mengalami komplikasi persalinan sebesar 79,2\%.

Menurut asumsi peneliti bahwa pengawasan antenatal merupakan pemeriksaan kehamilan untuk mengoptimalkan kesehatan mental dan fisik ibu hamil, sehingga mampu menghadapi persalinan masa nifas, persiapan memberikan ASI, dan pemulihan kesehatan reproduksi secara wajar.Asuhan antenatal adalah pemeriksaan kehamilan untuk melihat dan memeriksa keadaan ibu dan janin yang dilakukan secara berkala diikuti dengan upaya koreksi terhadap penyimpangan yang ditemukan selama kehamilan.

Pengaruh Deteksi Resiko Kehamilan terhadap Komplikasi Persalinan di Wilayah Kerja Puskesmas Karang Anyar Kecamatan BeringinKabupaten Deli Serdang.

Hasil penelitian tentang variabel deteksi resiko kehamilan ditemukan ibu yang terdeteksi resiko kehamilan dengan proporsi tidak ada komplikasi persalinan94,7\%. Uji statistik regresi logistic ganda menunjukkan variabel deteksi resiko kehamilan nilai $\mathrm{p}<0,05$ dengan odds rasio55,580(95\% CI $=5,816-531,148)$ berpengaruh terhadap komplikasi persalinan. Mengacu pada hasil uji tersebut dapat dijelaskan semakin terdeteksi resiko kehamilan akan meningkat tidak ada komplikasi persalinan. Pada penelitian ini perlu peningkatan deteksi resiko kehamilan pada ibu saat hamil karena ibu yang tidak terdeteksi resiko kehamilan mengalami komplikasi persalinan sebesar $78,2 \%$.

Ibu hamil dengan kehamilan resiko adalah ibu hamil dengan satu atau lebih faktor resiko baik dari pihak ibu maupun janinnya yang dapat memberikan dampak kurang menguntungkan bagi ibu maupun janinnya. Untuk itu perlu melakukan deteksi dini resiko tinggi kehamilan yang bertujuan agar menemukan ibu yang mempunyai faktor resiko yang berpeluang untuk terjadi kegawatdaruratan sedini mungkin pada saat persalinan (Wiknjosastro, 2007).
Menurut asumsi peneliti bahwa deteksi dini dalam pelayanan antenatal adalah mengarah pada penemuan ibu hamil beresiko agar dapat ditangani secara memadai sehingga kesakitan atau kematian dapat dicegah. Untuk pengenalan tanda-tanda kehamilan yang memiliki tanda bahaya dan komplikasi kehamilan banyak poster poster dan leaflet disebarkan kepada masyarakat khususnya ibu-ibu hamil yang berkunjung dalam pelayanan antenatal maupun pada kegiatan kunjungan rumah dalam pemantauan kesehatan masyarakat.

\section{KESIMPULAN DAN SARAN}

\section{Kesimpulan}

1. Ada pengaruh kunjungan ANC terhadap komplikasi persalinan di Wilayah Kerja Puskesmas Karang Anyar Kecamatan BeringinKabupaten Deli Serdang sehingga dapat dijelaskan semakin tinggi kunjungan ANC akan meningkat tidak ada komplikasi persalinan.

2. Ada pengaruh deteksi risiko kehamilan terhadap komplikasi persalinan di Wilayah Kerja Puskesmas Karang Anyar Kecamatan BeringinKabupaten Deli Serdang sehingga dapat dijelaskan semakin terdeteksi resiko kehamilan akan meningkat tidak ada komplikasi persalinan.

\section{Saran}

1. Kepada Dinas Kesehatan Kabupaten Deli Serdang dipandang perlu untuk merencanakan program pelatihan guna peningkatan kualitas pelayanan antenatal bagi tenaga kesehatan khususnya bidan yang ada di Kabupaten Deli Serdang.

2. Kepada tenaga kesehatan khususnya bidan di wilayah kerja Puskesmas Karang Anyar Kecamatan Beringin agar lebih aktif dalam memberikan dukungan serta penyuluhan kepada masyarakat khususnya ibu hamil baik di Puskesmas, Puskesmas Pembantu, tempat pengajian dan Posyandu dan perlu melibatkan kader Posyandu dan Tokoh Masyarakat agar masyarakat lebih memahami tentang pentingnya kunjungan antenatal kepada ibu hamil.

3. Kepada peneliti selanjutnya, diharapkan untuk melakukan penelitian lanjutan mengenai kualitas pelayanan dalam pelaksanaan antenatal sehingga dapat meningkatkan kesehatan ibu dan janin yang pada akhirnya dapat menurunkan angka kematian ibu maupun bayi.

\section{DAFTAR PUSTAKA}

Achadiat, 2003. Prosedur Tetap Obstetri dan Ginekologi. Penerbit Buku Kedokteran EGC. Jakarta.

Balitbangkes. 2013. Riset Kesehatan Dasar 2013. Kementerian Kesehatan Republik Indonesia, Jakarta. 
Badan Pusat Statistik, 2013, Profil Statistik Kesehatan, 2013. www.bps.go.id; diakses tanggal 12 April 2013.

Bellington, M, Dkk, 2007. Kegawatan Dalam Kehamilan Persalinan (Buku Saku Bidan). Alih Bahasa, Ariana F, Penerbit Buku Kedokteran EGC. Jakarta.

Dewi, 2010, Gambaran Pengetahuan Ibu Hamil tentang kehamilan Risiko di Puskesmas Bangetayu Kecamatan Genuk Kota Semarang 2010, Tesis, Fakultas Ilmu Keperawatan dan Kesehatan Universitas Muhammadyah Semarang

Depkes, 1997. Deteksi Dini Penatalaksanaan Kehamilan Risiko Tinggi. Pusat Pendidikan dan Latihan Pegawai Departemen Kesehatan Republik Indonesia, Jakarta.

2001. Rencana Strategis Nasional Making Pregnancy Safer (MPS) di Indonesia 2001-2010. Departemen Kesehatan Republik Indonesia, Jakarta.

, 2007. Materi Ajar Penurunan Kematian Ibu Dan Bayi Baru Lahir. Direktorat Bina Kesehatan Ibu, Direktorat Jenderal Bina Kesehatan Masyarakat, Departemen Kesehatan Republik Indonesia, Jakarta.

, 2008. Profil Kesehatan Indonesia 2007. Departemen Kesehatan Republik Indonesia, Jakarta.

2009. Pedoman Pemantauan Wilayah Setempat Kesehatan Ibu dan Anak (PWS-KIA). Jakarta.

Dinkes Provinsi Sumatera Utara, 2013, Profil Kesehatan Sumatera Utara, 2012, www.depkes.go.id; diakses tanggal 12 April 2014.

Dinkes Kabupaten Deli Serdang, 2013. Profil Kesehatan Kabupaten Asahan tahun 2012, Lubuk Pakam.

Hani, U. Kusbandiyah, J. Marjati dan Yulifah, R. 2011. Asuhan Kebidanan Pada Kehamilan Fisiologis, Salemba Medika, Jakarta.
Lemeshow, S., Hosmer, Jr, D, W., Klar, J. \& Lwanga, S. K. 1997. Besar sampel dalam penelitian kesehatan. Penerjemahan: Pramono, D. Gadjah Mada University Press, Yogyakarta.

Manuaba, I.B.G., I.A. Chandranita Manuaba, dan I.B.G. Fajar Manuaba. 2007, Pengantar Kuliah Obstetri, Buku Kedokteran EGC, Jakarta.

Misar, Y., Masni, Zulkifli, A., 2012, Faktor Risiko Komplikasi Persalinan pada Ibu Melahirkan di Kabupaten Gorontalo Utara tahun 2012, Hasil Penelitian, Dinas Kesehatan Gorontalo Utara

Moctar. R, 1998, Sinopsis Obstetri, Jilid 2, EGC, Jakarta

Musliahtun, W.N, 2009 . DokumentasiPelayananKebidanan,Fitramaya, Yogyakarta.

Notoadmodjo, S, 2003, Pengantar Pendidikan Kesehatan dan Perilaku Kesehatan, Jakarta, PT. Rineka Cipta 2006. Metodologi Penelitian Kesehatan (Edisi Revisi). Rineka Cipta, Jakarta.

Oxorn, H, 2010. Ilmu Kebidanan Patologi dan Fisiologi Persalinan. Alih Bahasa, Hakimi M, Penerbit Yayasan Essentia Medica. Yogyakarta.

Puskesmas Karang Anyar, 2013, Laporan Puskesmas Karang Anyar Tahun 2012, Kecamatan Beringin Kabupaten Deli Serdang.

Rukiyah, A.Y., dan Lia, Y., 2011, Asuhan Kebidanan IV (Patologi Kebidanan), cetakan kedua, Jakarta, Trans Info Medan.

Wiknjosastro, H., 1999, Ilmu Kandungan. Yayasan Bina Pustaka Sarwono Prawirohardjo, Jakarta. ., 2002, Ilmu Kebidanan, Yayasan Bina Pustaka Sarwono Prawirohardjo, Yogyakarta.

Yulifah, R., 2009,. Asuhan Kebidanan Komunitas, Salemba Medika Jakarta. 